\title{
Avaliação do Resultado Estético em Pacientes Submetidas a Ressecção de Mama Supranumerária Axilar
}

\author{
Evaluation of the Cosmetic Result in Patients Submitted to Resection of an Axillary \\ Supernumerary Breast
}

Marcus Cavalcante de Oliveira, Lúcia Taia, Antônio Rosário Leite Filho

Ruffo de Freitas Júnior

\begin{abstract}
RESUMO
Objetivos: avaliar o grau de satisfação das pacientes submetidas a exérese de mamas acessórias, considerando a estética e a taxa de complicações.

Pacientes e Métodos: foram avaliadas 23 pacientes submetidas a tratamento cirúrgico para remoção de tecido mamário axilar, no Serviço de Mastologia do HC-UFG, entre julho de 1994 e setembro de 1997. A idade variou entre 20 e 49 anos (média de 35 anos). As queixas das pacientes eram: dor local, desconforto e as referentes à estética corporal. A satisfação das pacientes foi avaliada por meio de entrevista, na qual elas se diziam muito satisfeitas, satisfeitas, insatisfeitas ou arrependidas da cirurgia. A equipe do HC-UFG também fez sua avaliação de cada uma das pacientes, na qual o resultado cosmético foi classificado como muito bom, bom ou ruim.

Resultados: de acordo com a avaliação das pacientes, 61\% estavam muito satisfeitas e nenhuma estava arrependida da cirurgia; a avaliação da equipe médica foi mais rigorosa, uma vez que apenas $26 \%$ dos casos foram considerados como muito bom pelos examinadores. Com relação às complicações, houve ocorrência de seroma em $22 \%$ e de infecção em $13 \%$ dos casos.

Conclusão: a divergência entre os resultados das pacientes e dos médicos parece mostrar que o grau de satisfação das primeiras é muito maior do que inicialmente podíamos imaginar, incentivando-nos a continuar a oferecer este tratamento àquelas que assim o desejarem.
\end{abstract}

UNITERMOS: Mamas: doenças benignas. Mamas extranumerárias. Cirurgia: complicações.

\section{Introdução}

Dentre as anomalias de desenvolvimento das mamas, a polimastia está entre as mais freqüentes ${ }^{1}$. Ela consiste na persistência do tecido mamário ao longo da linha láctea ${ }^{2,3}$, que se estende da axila à região inguinal, incidindo em 1 a $2 \%$ das mulheres de raça branca ${ }^{1,4,5}$ e, em $90 \%$ dos casos, localiza-se no tórax, especialmente na região axilar ${ }^{1}$. Fora da linha mamária, é chamada de tecido aberrante,

Setor de Mastologia do Departamento de Ginecologia e Obstetrícia da Faculdade de Medicina da Universidade Federal de Goiás.

Correspondência:

Ruffo de Freitas Júnior

Alameda das Rosas, 533, Setor Oeste

74110-060 - Goiânia - GO

Fone/fax: (62) 212-2049 ou pseudomama ${ }^{6}$ Geralmente, a ocorrência é bilateral e manifesta-se com maior freqüência no periodo puerperal ${ }^{1,3}$.

Embora a maioria dos autores afirmem não haver risco aumentado para malignização desse tecido, alguns admitem que haja chances aumentadas de evolução neoplásica ${ }^{5,7,8,9}$. Também parece haver associação entre mamas extranumerárias e malformações renais ${ }^{10}$.

Para o tratamento das pacientes portadoras de mamas extranumerárias, existe sempre a dificuldade de se indicar a cirurgia de modo sistemático ou não, considerando que, apesar de ser um procedimento de pequeno porte, a inexistência de clara divisão entre tecido ectópico, gordura e mama normal pode dificultar o ato operatório, por vezes impossibilitando um 
procedimento adequado e causando ressecções incompletas ou às vezes, excessivas. Isto acaba por acarretar um resultado cosmético inadequado.

Assim, o objetivo deste trabalho foi fazer uma avaliação pós-operatória das pacientes submetidas à exérese de mamas ectópicas axilares, analisando sua satisfação com o resultado estético e a motivação para a cirurgia, considerando ser este um aspecto pouco explorado na literatura.

\section{Pacientes e Métodos}

Foram avaliadas 23 pacientes submetidas a exérese de glândula mamária extranumerária no Serviço de Mastologia do Hospital das Clínicas da Universidade Federal de Goiás, no período de julho de 1994 a setembro de 1997.

A idade dessas pacientes variou entre 20 e 49 anos (média de 35 anos), sendo que 13\% delas eram menopausadas. Os motivos das consultas foram: preocupação com a estética, desconforto e dor local. Ao exame clínico das mamas não se evidenciaram alterações tais como nódulos, cistos ou descargas mamilares. Após o atendimento, descartadas outras doenças associadas, era oferecida à paciente a possibilidade de exérese ou somente o seguimento.

As pacientes que preferiram o tratamento foram operadas em ambiente cirúrgico, sob anestesia geral, utilizando-se incisão axilar elíptica, com ressecção de pele e do tecido mamário ectópico de acordo com o julgamento do cirurgião, conforme técnica previamente preconizada ${ }^{7}$.

Os espécimes cirúrgicos foram avaliados macro e microscopicamente, após fixação em formol a $10 \%$. Os volumes variaram entre 42 e $216 \mathrm{~cm}^{3}$ (média de $101,5 \mathrm{~cm}^{3}$ ) e em seis casos foi apenas aferido o peso da peça, que variou de 40 a $60 \mathrm{~g}$. Os achados do estudo anatomopatológico das peças mostrou tecido mamário normal em todas, sem alterações funcionais ou estruturais.

A satisfação da paciente, em relação ao resultado cosmético, foi avaliada por meio de entrevista, realizada num periodo entre 5 e 43 meses após a cirurgia. Nessa entrevista a paciente graduava sua satisfação com o resultado da cirurgia em: muito satisfeita, apenas satisfeita, insatisfeita ou arrependida.

O resultado pós-cirúrgico foi também avaliado pela equipe de Mastologia do HC-UFG, que o considerou como: muito bom, bom ou ruim. Os critérios de avaliação foram: aspecto e tamanho da cicatriz, presença de seqüelas, presença de desconforto e/ou dor ou resquícios de tecido mamário.

\section{Resultados}

Os resultados encontrados na presente série mostram que 14 pacientes estavam muito satisfeitas, sete referiam apenas satisfação e apenas duas estavam insatisfeitas. Nenhuma estava arrependida de ter sido submetida à cirurgia (Figura 1).

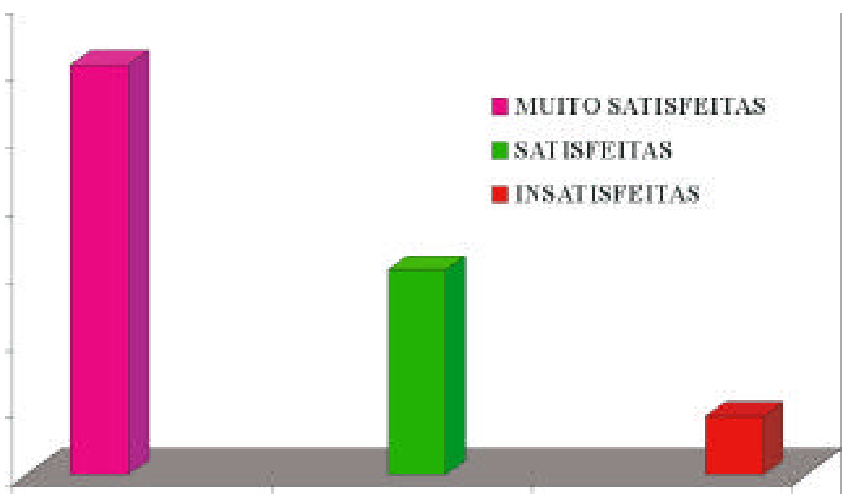

Figura 1 - Grau de satisfação das pacientes submetidas a exérese de mamas extranumerárias, em porcentagens.

Também foram avaliadas as queixas póscirúrgicas, sendo que 12 pacientes não apresentavam nenhuma queixa, enquanto duas reclamaram de tecido mamário residual, 10 de dor e outras duas de hipoestesia cutânea (Figura 2).

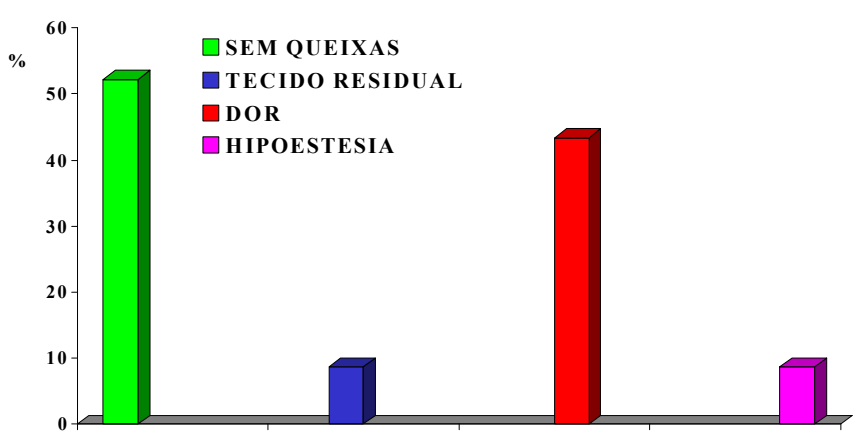

Figura 2 - Queixas pós-operatórias apresentadas pelas pacientes, em porcentagens.

A equipe do Serviço de Mastologia considerou "muito bom" o resultado em seis pacientes. Em 10 delas, a avaliação foi apenas "bom" e em sete o resultado foi "ruim" (Figura 3).

Quanto às complicações imediatas da cirurgia, ocorreram seromas em cinco delas $(22 \%)$ e infeção em três (13\%) e uma paciente apresentou seroma e infeção concomitantes. Dezesseis pacientes não apresentaram qualquer complicação. 


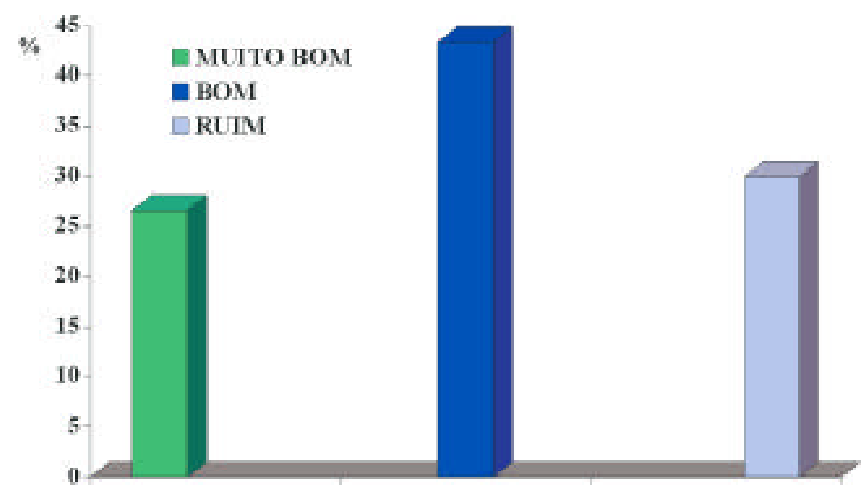

Figura 3 - Avaliação dos resultados pela equipe de mastologia, em porcentagens.

\section{Discussão}

O tecido mamário ectópico axilar pode ser dividido em 8 categorias: 1) presença de mama completa com tecido glandular mamário e complexo aréolo-mamilar; 2) presença de tecido glandular e mamilo; 3) tecido glandular e aréola; 4) somente tecido glandular; 5) complexo aréolo-mamilar com substituição do tecido glandular por tecido adiposo (pseudomama); 6) mamilo solitário (politelia); 7) aréola solitária (politelia areolar); 8) presença de um pequeno setor de tecido com pelos (politelia pilosa $)^{2}$.

As lesões citadas acima são freqüentes e bem descritas na literatura. Entretanto, a grande maioria dos trabalhos tenta associar o tecido mamário ectópico a outras malformações, principalmente aquelas do aparelho renal ${ }^{10}$. Outros trabalhos tentam associar o tecido ectópico a tumores mamários, desde fibroadenomas até carcinomas $^{4,5}$. Assim, pouco tem sido escrito a respeito do tratamento cirúrgico das mamas supranumerárias axilares, suas dificuldades e, principalmente, sobre o resultado cosmético advindo desta terapêutica.

De uma forma geral, a conduta nos casos de mamas axilares supranumerárias consiste em tranqüilizar a paciente, explicando a ela o caráter de benignidade do tecido ectópico e a sua origem embriológica. Por vezes, o desconforto, dor e, principalmente, o fator estético conduzem a paciente a solicitar que o cirurgião faça a ressecção do tecido ectópico. No presente material, pudemos observar que mais de $50 \%$ das pacientes solicitaram a ressecção da glândula mamária axilar por motivos estéticos. Já na casuística de Pitanguy, as queixas mais comuns foram o desconforto na região axilar, o aumento de volume nos ciclos menstruais e a dor ${ }^{11}$

A técnica cirúrgica é bem conhecida e tem sido descrita em alguns trabalhos científicos ${ }^{11}$. Não obstante, como não há uma nítida passagem entre o tecido mamário tópico e o tecido ectópico, incluindo também a impossibilidade de se distinguir adequadamente entre o tecido mamário e o tecido adiposo, durante o procedimento cirúrgico, não há um plano anatômico que possa dizer ao cirurgião qual o caminho que ele deva tomar com o seu bisturi. Desta maneira, sempre existe a possibilidade de se ressecar uma grande quantidade ou uma quantidade insuficiente do tecido mamário ectópico. Isso causaria defeitos cosméticos, como a deformidade de uma axila profunda ou a persistência de mama residual, respectivamente.

Outro problema em relação ao resultado cosmético se refere ao tamanho da incisão, uma vez que, nos casos em que há um excesso de pele associado ao parênquima mamário ectópico, se faz necessária a ressecção de parte da pele que cobre o tecido ectópico. Quanto mais ampla a ressecção, maior será a cicatriz final, por vezes se estendendo da linha axilar anterior à linha axilar posterior. Uma das possibilidades para se tentar reduzir o tamanho da incisão é a utilização da zetaplastia, porém, algumas pacientes poderão apresentar uma cicatrização inadequada em razão da posição da sutura não respeitar as linhas de força desta região.

A possibilidade de lesão de estruturas importantes está sempre presente. Some-se a isto o fato de que há uma vasta gama de complicações que podem e freqüentemente acontecem, como por exemplo, hematomas, seromas e infecção ${ }^{1} . \mathrm{Na}$ presente série, também observamos uma alta taxa de complicações, principalmente seromas e infecções.

Os resultados desta investigação mostram, para nossa surpresa, que o grau de satisfação das pacientes foi maior do que inicialmente poderiamos supor. Em nossa casuística, a quantidade de pacientes satisfeitas ou muito satisfeitas com os resultados de seu tratamento superou $90 \%$ do total de mulheres estudadas. Este número contrasta com os valores encontrados quando da avaliação da satisfação pelos médicos do Serviço de Mastologia do HC-UFG, que considerou insatisfatório o resultado em um quarto dos casos.

Esses dados parecem nos indicar que, embora haja por parte dos mastologistas um rigor acentuado para avaliação positiva do tratamento cirúrgico das mamas supranumerárias, a percepção de beneficio pelas pacientes é muito maior do que, em principio, imaginávamos.

Apesar da necessidade de se confirmar os dados aqui apresentados, o alto grau de satisfação das pacientes aponta uma realidade que, até então, era pouco percebida para esse procedimento, nos incentivando para que continuemos a oferecer a 
exérese do tecido mamário extranumerário sempre que a paciente assim o desejar.

\section{ABSTRACT}

Purpose: to evaluate the degree of satisfaction of patients submitted to resection of a supernumerary breast, in terms of esthetics, and the rate of complications.

Patients and Methods: twenty-three women submitted to surgical treatment for removal of axillary breast tissue at the Breast Unit of the HC-UFG, between July 1994 and September 1997, were evaluated. Age ranged between 20 and 49 (mean 35 years). Patient complaints included local pain, discomfort and questions on personal esthetics. The patients' satisfaction was evaluated through an interview in which they reported to be very satisfied, satisfied, unsatisfied or regretting the surgery. The HC-UFG team also evaluated each of these patients, considering the cosmetic result as very good, good or poor. Results: according to the evaluation by the patients themselves, $61 \%$ were very satisfied and none regretted the surgery. The evaluation carried out by the medical team was stricter, as only $22 \%$ of the cases were rated as very good by the evaluators. In terms of complications, there was a $22 \%$ incidence of seroma and $13 \%$ of infection.

Conclusion: the discrepancy among the patients' and doctors' ratings seems to demonstrate that the degree of satisfaction of the patients is higher than that one could initially suppose, a fact that motivates us to carry on offering this treatment modality to those who wish to have it, even considering the relative high rate of complications.

KEY WORDS: Supernumerary breasts. Surgery complications.

\section{Referências}

1. Haagensen CD. Diseases of the breast. 3 ed. Philadelphia: W.B. Saunders; 1986.

2. Bland KI, Copeland III M. La mama: manejo multidisciplinario de las enfermedades benignas y malignas. Buenos Aires: Panamericana, 1991.

3. Velanovich V. Ectopic breast tissue, supernumerary breasts, and supernumerary nipples. South Med J 1995; 88: 903-6.

4. Andrade FF, Ramos CCF. Fibroadenoma em mama supranumerária axilar: relato de um caso. J Bras Ginecol 1994; 104: 199-200.

5. Piza BT. Fibroadenomas em mama supranumerária axilar. J Bras Ginecol, 1993; 103: 13-4.

6. Koltuksuz U, Aydin E. Supernumerary breast tissue: a case of pseudomamma on the face. J Pediatr Surg 1997; 32: 1377-8.

7. Cellini A, Offidani A. Familial supernumerary nipples and breast. Dermatology 1992; 185: 56-8.

8. Marshall MB, Moyniham JJ, Frost A, Evans SRT. Ectopic breast cancer: case report and literature review. Surg Oncol 1994; 3: 295-304.

9. Sampaio Neto LF, Barbo MLP, Menegoci JC. Polimastia axilar: aspectos morfológicos. Rev Bras Ginecol Obstet, 1994; 16: 182-4.

10.Ubani CE, Betti R. Aberrant mammary tissue and nephrourinary malignancy: A man with unilatual polythelia and ipsilateral renal adnocarcinoma associated with polycystic kidney disease. Cancer Genet Cytogenet 1996; 87: 88-9.

11.Pitanguy I, Sinder R, Salgado F, Radwanski HN. Tratamento cirúrgico das deformidades benignas da glândula mamaria: Parte II. Rev Bras Cir 1994; 84: $123-46$. 